\title{
Pharmacovigilance in Cabo Verde: Measuring the Awareness and Knowledge by Healthcare Professionals
}

\author{
Carla Djamila Reis ${ }^{1^{*}}$, Calida Etezana Veiga ${ }^{2}$ andJailson Jesus Martins ${ }^{3}$ \\ ${ }^{1,2,3}$ Agência de Supervisão e Supervisão de Produtos Farmacêuticos e Alimentares (ARFA), Praia, Cape Verde
}

*Corresponding author: Carla Djamila Reis, Master in Pharmaceutical Regulation, Agência de Regulação e Supervisão de Produtos Farmacêuticos e Alimentares (ARFA), Praia, Cape Verde, Tel: 23826264 10; E-mail: djamila.reis@arfa.gov.cv

Received date: August 27, 2015; Accepted date: September 10, 2015; Published date: September 15, 2015

Copyright: (c) 2015 Reis CD, et al. This is an open-access article distributed under the terms of the Creative Commons Attribution License, which permits unrestricted use, distribution, and reproduction in any medium, provided the original author and source are credited.

\section{Introduction}

The broad access to therapeutic innovation since the second quarter of the 20th century brought significant gains to public health but also safety concerns associated with their use because medicines represents a risk and the benefit/risk ratio changes during the post-marketing phase. Adverse drug reactions (ADR's) and drug related problems (DRPs) are therefore a major and worldwide problem for both health and sustainable development, the reason why pharmacovigilance (PV) must gain such an important role in the early detection of the issues and the prevention of the ADRs through monitoring and minimization tools.

The study conducted by Lazarou in 1998, concluded that, despite the heterogeneity of the meta-analysis, the overall incidence of ADRs was $10.9 \%$ in hospitalized patients, of which $6.7 \%$ serious, 0.32 fatal\% and $15.1 \%$ when considering ADR's that caused hospitalization or occurred during it [1]. The study emphasizes the large number of serious ADRs in situations of correct prescription and administration of medicines.

The measurement of the ADR's as a cause of hospitalization varies between $2-6 \%$ and 10 to $20 \%$ of hospitalized patients [2] however, other published studies estimate an incidence ranging between $0.86 \%$ in Australia, 23\% in the United States and 37\% in the Netherlands [3].

Despite this variability, in a context indicating approximately 197.000 deaths/year in Europe due to ADRs [4], the relevance of monitoring ADR's is well established stressing the need for further studies.

Other study by Stausberg described the occurrence of ADR's as cause of $5-10 \%$ of the hospitalizations, the same probability of occurrence during hospitalization, of which a proportion of about 30 to $40 \%$ considered preventable ADRs [5].

In Africa, despite the increase in access to medicines in the past three decades, the data about the impact of ADRs is still incipient, conditioned mostly by the state of development of the countries. Nevertheless, it is estimated that 4.5 to $8.4 \%$ of hospital admissions are due to ADR's, 1.5 to $6.3 \%$ are cause of hospitalization, 6.3 to $49.5 \%$ of ADR's occurs during hospitalization and $14 \%$ of ADRs in the Moroccan Anti Poison and Pharmacovigilance Center database were classified as preventable error [6-8].

Another study, in a Tunisian hospital identified a median of $9.2 \%$ occurrence ADR's during hospitalization and $27 \%$ to $69.6 \%$ preventable or due to negligence [9].

In this context, $\mathrm{PV}$ is an essential science for public health protection and an important tool to ensure the quality, effectiveness and safety of consumers, contributing to the rational use of medicines.
Therefore, this is the framework for the need for a functional PV system in every country.

The PV systems in African countries, like those in developed countries, are based essentially on spontaneous reporting system and Cabo Verde will not be an exception.

Cabo Verde is a small archipelagic developing country, very dependent on the international supply of pharmaceuticals products and, until 2013, lacking a formal PV system to detect and predict ADRs. In addition to benefits to patient safety by reducing mortality and morbidity, its implementation can be an instrument to support rational management of medicine expenses in addition to characterize the magnitude and impact of this problem already described internationally.

The spontaneous reporting system, used since the beginning of the implementation of PV systems in the late 60 s is the most cost-effective tool to establish and support the functioning of a PV system. It is a widely used method as source of information for signal detection, which fundamentally depends on the participation of healthcare professionals (HCP's) [10,11].

However, the main constrain regarding the effectiveness of the spontaneous reporting system is underreporting, with the consequent limitations in assessing the risk of the drug and delay in detecting signs of risk $[12,13]$. Indeed, it is estimated that the spontaneous reporting method only identifies one in twenty reactions occurred due to underreporting.

As the identification of a suspected ADR is a crucial step, the knowledge, the awareness and behavior of HCP's regarding PV, represents a major challenge $[12,14]$.

Thus, in the context of framing a project of a functional model for a PV system adapted to the reality of Cabo Verde and considering the role of HCP's for spontaneous reporting, a questionnaire was distributed to characterize the knowledge and recognition of the importance of PV by HCP in Cabo Verde.

\section{Method}

The study was conducted with the distribution of a questionnaire before the start of sensitization sessions on PV whose schedule was announced as part of the launch of a pilot project to establish a spontaneous reporting system.

The questionnaire we developed was based on other studies designed to address the knowledge and attitudes of HCP's [15-17] and adapted to the reality of Cabo Verde. It was two pages long and divided into the following sections: (1) demographic data, such as age, 
sex, workplace, profession; (2) knowledge regarding PV and (3) statements regarding attitudes to spontaneous ADR reporting.

The questionnaire was drawn by a multidisciplinary team with pharmaceutical, biomedical and statistical background, working at Food and Drug Regulatory Agency (Agência de Regulação e Supervisão dos Produtos Farmacêuticos e Alimentares -ARFA).

The questionnaire was personally distributed to 356 HCP's who attended to the sensitization sessions on PV, from April to June 2013. The number of HCPs represents more than $30 \%$ of the total in the country. The sensitization sessions occurred in public healthcare facilities involving HCP's from hospitals, health centers, private clinics and pharmacies in Santo Antão, S. Vicente, S. Nicolau, Sal, Boa Vista, Santiago, Fogo and Brava, 8 of the 9 inhabited islands of Cabo Verde.

The database and analysis was done using Statistical Package for Social Sciences, version 20.0 (SPSS Inc).

For the descriptive analysis of results, association chi-square tests were performed with $95 \%$ confidence level that allow to check the independence between two indicators studied and to measure the intensity of the association.

Automatic rules for database validation were used during the data analysis phase.

\section{Results}

The distribution of questionnaire originated 331 answers, representing a response rate of $92.9 \%$. The characterization of the population that responded to the questionnaire in terms of age indicates that $60.5 \%$ of those surveyed professionals were under 40 years old.

The average age is 38.48 years, distributed between the minimum age of 17 years and maximum of 64 years. As regards to gender, $65.6 \%$ are female and as for workplace, almost half (49.8\%) worked in health centers, $31.1 \%$ in private health sector and $19.0 \%$ in hospitals.

Most of the respondents were from Santiago Island (45.0\%), which is expected since it is the biggest island in the country.

In the context of this questionnaire, it was relevant to characterize the distribution by profession and workplace. Most of attendance was nurses with $30.2 \%$, followed by physicians with $22.4 \%$ and $12.1 \%$ of pharmacists.

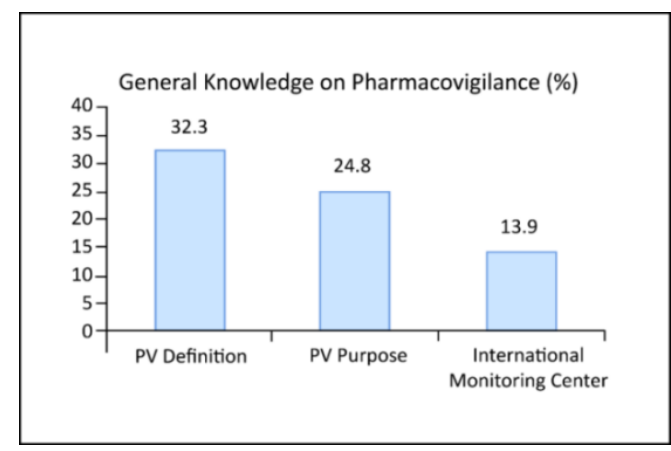

Figure 1: General knowledge on Pharmacovigilance
After the demographic characteristics, the questions were about the general knowledge of PV. The Figure 1 shows the knowledge of HCPs about the definition of pharmacovigilance, it purpose and information concerning the international drug monitoring program.

In general, more than $1 / 3$ of respondents recognized the definition of PV, for $3 / 4$ of those involved the purpose was not clear and only $13.9 \%$ identified the location of the international monitoring center in Uppsala Monitoring.

The Figure 2 shows their sensitivity concerning PV. As can be seen, most of the respondents considered that the reporting of suspected ADRs and DRP's should be an obligation for HCP's. Regarding their opinion about which professionals should report, the majority considered that physicians, pharmacists and nurses should all report (Figure 3).

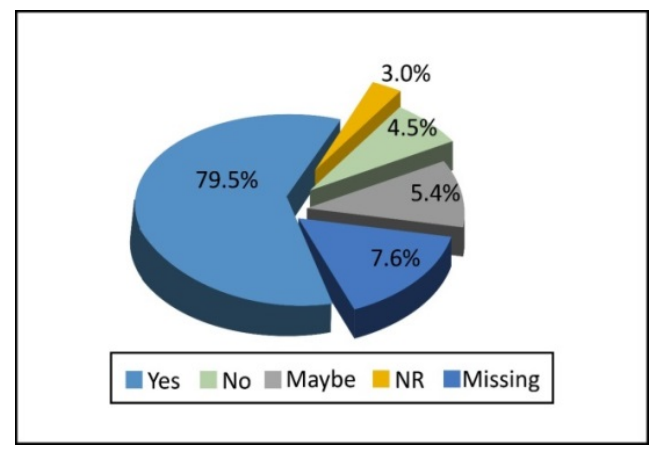

Figure 2: Reporting as HCP obligation

In the sample under analysis, $66.6 \%$ of the professional claimed to have read a scientific article on PV.

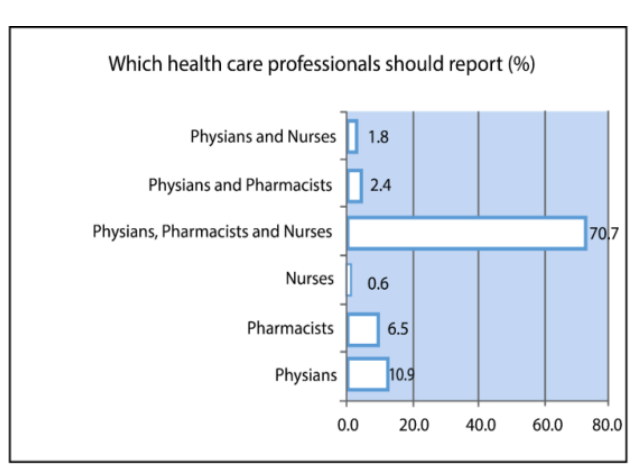

Figure 3: Which HCPs should report

As for the knowledge of the existence of a PV pilot project in Cabo Verde and the existence of a reporting form, the answers were negative for about $50 \%$ of respondents to both questions. However, when asked about an operational element there was a reasonable knowledge that the National PV Centre is planned within ARFA and that the system will be supported by a spontaneous reporting methodology (Figure 4). 


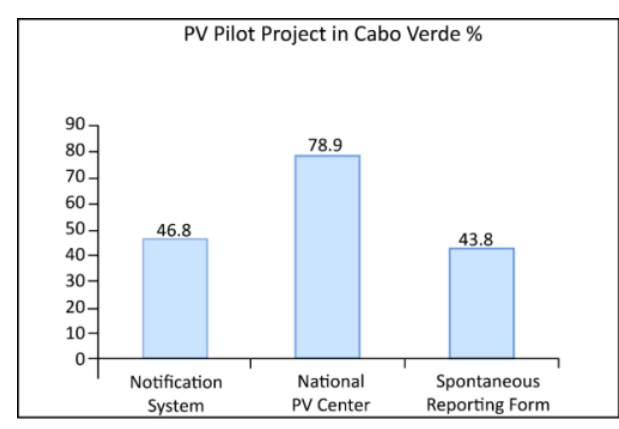

Figure 4: Operating elements of the PV pilot project in Cabo Verde

The questions to characterize the attitude of HCPs were if they had reported already, if they had filled a reporting form and in case they did if they send it.

The Figure 5 shows the attitudes of HCPs towards the reporting of ADRs. In general, the answers were negative.

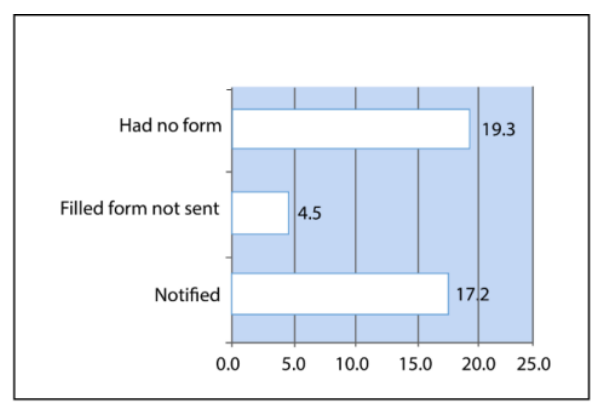

Figure 5: HCP attitude regarding reporting

To characterize the HCPs that reported already, $28.1 \%$ were nurses, $21.1 \%$ were pharmacists, $19.3 \%$ were physicians, $54.4 \%$ were from Santiago island and $40.4 \%$ worked in health centers while only $12.3 \%$ in hospitals.

Among the HCP who claims to have no access to the reporting form, 32\% were physicians, $29.7 \%$ were nurses, $10.9 \%$ pharmacists and $43.3 \%$ of them worked in health centers, $34.4 \%$ in private health sector and $21.9 \%$ in hospitals.

As for the health care professional that fulfilled the reporting form but did not sent it $66.7 \%$ live in Santiago Island, $40 \%$ were pharmacists, $20 \%$ were physicians and $60 \%$ worked in the private sector.

The question about the reasons not to report was left blank by $54.1 \%$ of respondents. The Figure 6 identify the main reasons for nonreporting. The lack of time was identified as the main reason but the lack of financial incentive and the perception that an isolated case may not be relevant were also appointed.

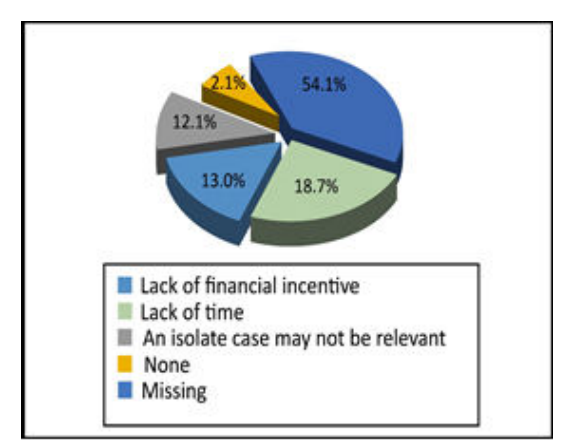

Figure 6: Reasons for non-reporting

\section{Discussion}

This survey was conducted in the context of framing a project of a functional model for a Pharmacovigilance system adapted to Cabo Verde.

First step was to characterize the illegal sale of medicines and to identify the main predisposing factors. It was possible to quantify the problem, to identify the geographic distribution and main reasons to use the illegal medicines market. The study has shown the significant magnitude of the problem and that the population has no perception of risk in purchasing medicines in illegal market, a role normally assumed by HCP. Therefore, among conclusions, the need for awareness sessions and to characterize the knowledge and recognition of the importance of PV by HCP.

The aim of this study was to describe the sample characteristics of HCP that attended to sensitization sessions on PV and assess relationship with some of the variables with the results.

In this sample that represents $1 / 3$ of total HCPs in Cabo Verde, the response rate of $92.9 \%$ shows that the HCP's were motivated to collaborate. It is also important to notice that, in this early phase of establishing a PV system in Cabo Verde, the basic knowledge about PV were present for more than $1 / 3$ of the respondents. It was positive to identify that the majority believe that reporting ADRs is an obligation of HCP's. Moreover, the perception that PV is a "teamwork" is an important first step to get them involved in this system.

One of the drawback verified is that although the general knowledge of PV, 73.4\% of HCPs had never reported a suspected ADR or DRP and $9.4 \%$ did not respond. The surveyed sample had $54.8 \%$ of professionals under 40 year-old, $30.2 \%$ of nurses, $45 \%$ living in Santiago Island and $49.8 \%$ worked in health centers. When comparing with the population that already reported more than $64.5 \%$ is less than 40 years old, $28.1 \%$ are nurses, $54.4 \%$ is resident at Santiago and $40.4 \%$ worked in health centers. This results could indicate a relationship between age, profession, island of residence and workplace or just be the reflex of the national reality where the majority of the population is young (average 27.8), the HCP's at higher proportion are nurses, more than half the population lives at Santiago island and the public health sector captures most of HCP's.

Therefore, chi-square tests were used to identify dependent relationship between the attitudes regarding reporting with age, profession, island of residence and workplace. There was no relation identified with age $(\mathrm{p}=0.187)$ and island of residence $(\mathrm{p}=0.09)$. 
Regarding profession, the relationship is very weak $(\mathrm{p}=0.030)$ but it seems to exist some relation with workplace $(\mathrm{p}=0.022)$.

The reasons for not reporting identified in this sample are in line with those identified in published studies $[13,18]$ such as, lack of time, lack of financial incentive and the perception that an isolated case may not be relevant. Despite most of the respondents feel that they have a professional obligation to report ADRs, they appointed the lack of financial incentives as one of the reason not to report.

Nevertheless, considering that, the question regarding the reasons not to report was left blank by $54.1 \%$ of respondents, further studies and intervention should be done to clarify that issue.

The outcome of $17.2 \%$ of HCP having reported already seems to indicate a bias that reflects the tendency to respond according to what is expected or known to be correct. This conclusion is due to comparison with the response on the knowledge of the existence of the pilot project of reporting system and the existence of a reporting form (less than a half), plus the comparison of spontaneous reports received by the National PV Centre in the respective year.

According to the survey, $17.2 \%$ of HCP's involved already reported what should mean approximately 57 reports. During 2013 and until September, the National Center received only 9 spontaneous reports. However, until December the reports increased reaching a total of 40 reports.

Another bias to identify is that the sample of HCP's that answered to the questionnaire represents the professional already interested since they decided to participate on a PV sensitization session and to fulfil the questionnaire.

As for the problem of underreporting, it is multifactorial and persists even within well- established PV systems. It was expected to confirm it in Cabo Verde where the system is not even formalized. This result is in line with a systematic review study [18] where the conclusion is that the knowledge and attitudes of health professionals are more related to the spontaneous reporting process than to the personal and professional factors [19-21].

\section{Conclusion}

This first time study in Cabo Verde concludes that there is general knowledge and recognition of the importance of PV by HCP in Cabo Verde. Despite the fact that reporting of suspected ADRs and DRP's were identified to be an obligation for HCP's, the non- reporting attitude was evident for several reasons.

The importance of this assessment is that it will be possible to plan educational interventions in order to increase the rate of spontaneous reporting.

Considering that no relation between the reporting attitudes was identified with age, island of residence and is very weak with profession, we may conclude that training interventions are expected to have impact and should consider the workplace that proven to have some influence.

Thus, other measures must be implemented in this context of establishing a PV system in Cabo Verde. Just to mention a few, periodic awareness sessions on the importance of spontaneous reporting, simple and on-line reporting process that could supersede the access to the reporting form and more specific training for identified HCP's that could be opinion leaders in promoting PV.
Even so, it will take time for spontaneous reporting information exists in quantity and quality to allow the necessary analysis to monitor the benefit-risk ratio and to generate signals. Therefore, the design of a PV model adapted to the reality of Cabo Verde requires further diagnostic studies and awareness promotion involving crucial players for a PV system, particularly in hospitals.

\section{Acknowledgement}

To the Agency for Regulation and Supervision of Pharmaceutical and Food (ARFA) for sponsoring the study and the permission to use the information.

\section{References:}

1. Lazarou J, Pomeranz BH, Corey PN (1998) Incidence of adverse drug reactions in hospitalized patients: a meta-analysis of prospective studies. JAMA 279: 1200-1205.

2. Pirmohamed M, Breckenridge AM, Kitteringham NR, Park BK (1998) Adverse drug reactions. BMJ 316: 1295-1298.

3. Davies EC, Green CF, Mottram DR, Pirmohamed M (2007) Adverse drug reactions in hospitals: a narrative review. Curr Drug Saf 2: 79-87.

4. European Commission (2008) Strengthening pharmacovigilance to reduce adverse effects of medicines.

5. Stausberg J, Hasford J (2011) Drug-related admissions and hospitalacquired adverse drug events in Germany: a longitudinal analysis from 2003 to 2007 of ICD-10-coded routine data. BMC Health Serv Res 11:134.

6. Safety of Medicines in Sub- Saharan Africa: Assessment of Pharmacovigilance Systems and their Performance (2011) US Agency for International Development by the Strengthening Pharmaceutical.

7. Tumwikirize W, Ogwal-Okeng JW, Vernby A, Anokbonggo WW, Gustafsson LL, et al. (2011) Adverse drug reactions in patients admitted on Internal Medicine wards in a district and Regional Hospital in Uganda. Afr Health Sci 11: 72-78.

8. Bencheikh RS, Benabdallah G (2009) Medication errors: pharmacovigilance centres in detection and prevention. $\mathrm{Br} \mathrm{J}$ Clin Pharmacol 67: 687-690.

9. Bouafia N, Bougmiza I, Bahri F, Letaief M, Astagneau P, et al. (2013) Ampleur et impact des évènements indésirables graves liés aux soins: étude d'incidence dans un hôpital du Centre-Est tunisien. Pan Afr Med J 16: 68 .

10. Naessens JM, Campbell CR, Huddleston JM, Berg BP, Lefante JJ, et al. (2009) A comparison of hospital adverse events identified by three widely used detection methods. Int J Qual Health Care 21: 301-307.

11. Araujo AC and Prisca SS (2003) Sistema de Notificação Espontânea, Farmacovigilância em Portugal. INFARMED.

12. Maria S, Gomes M (2001) Notificação de reacções adversas medicamentosas: sua relevância para a saúde pública. Revista Portuguesa de Saúde Pública.

13. Hazell L, Shakir SA (2006) Under-reporting of adverse drug reactions : a systematic review. Drug Saf 29: 385-396.

14. Giordani F, Rozenfeld S, de Oliveira DF, da Silva Versa GL, Terencio JS, et al. (2012) Surveillance of adverse drug events in hospitals: implementation and performance of triggers. Rev Bras Epidemiol 15: 455-467.

15. Carvalho JdP (2011) Estratégias para a elaboração do plano de farmacovigilância considerando o conhecimento e opinião dos profissionais de uma indústria pública/Strategies for developing pharmacovigilance plan considering the knowledge and opinions of industry professionals in a public. Escola Nacional de Saúde Pública Sergio Arouca Rio de Janeiro.

16. Pernas SIdS (2009) Farmacovigilância: As atitudes dos enfermeiros perante a notificação. Universidade de Aveiro. 
Citation: Reis CD, Veiga CE, Martins JJ (2015) Pharmacovigilance in Cabo Verde: Measuring the Awareness and Knowledge by Healthcare Professionals. J Pharmacovigil 3: 177. doi:10.4172/2329-6887.1000177

Page 5 of 5

17. Rajesh R, Vidyasagar S, and Varma DM (2011) An Educational Intervention to assess Knowledge Attitude Practice of pharmacovigilance among Health care professionals in an Indian tertiary care teaching hospital. International Journal of PharmTech Research 3: 678-692.

18. Lopez-Gonzalez E, Herdeiro MT, Figueiras A (2009) Determinants of under-reporting of adverse drug reactions: a systematic review. Drug Saf 32: 19-31.

19. Herdeiro MT, Figueiras A, Polónia J, Gestal-Otero JJ (2005) Physicians attitudes and adverse drug reaction reporting: a case-control study in Portugal. Drug Saf 28: 825-833.
20. Herdeiro MT, Figueiras A, Polónia J, Gestal-Otero JJ (2006) Influence of pharmacists' attitudes on adverse drug reaction reporting: a case-control study in Portugal. Drug Saf 29: 331-340.

21. Ribeiro-Vaz I, Herdeiro MT, Polónia J, Figueiras A (2011) Strategies to increase the sensitivity of pharmacovigilance in Portugal. Rev Saude Publica 45: 129-135. 